\title{
The BOR is changing its submission instructions
}

Sigmar de Mello Rode Executive Editor
Collowing its current policy of increasing its qualification and international participation, the Brazilian Oral Research (BOR) is changing its submission instructions. Hence, as of this issue, the print version of the instructions will no longer be published. They will be available only on-line, at both the SBPqO (Brazilian Division of the IADR) and the SCIELO sites. The editorial space thus made available will allow an additional article to be published per issue.

The BOR will also follow the recommendations made by BIREME, the World Health Organization (WHO) and the International Committee of Medical Journal Editors (ICMJE), namely, that all scientific journals should require authors to submit a registration number when submitting clinical trials for publication. Accordingly, as of July 1, 2008, only clinical research reports that have received this identification number from one of the Clinical Trial Registries validated by the criteria set by the WHO and by the ICMJE will be accepted for publication. The identification number must be presented after the abstract of the article submitted.

The aim of this requirement is to make public and transparent the existence of all clinical trials, irrespective of their positive, negative or inconclusive results.

Reinforcing its internationalization, BOR texts will now be entirely in English; consequently, submission of an abstract and descriptors in Portuguese will no longer be required. This requirement has frequently been considered an obstacle to authors from other countries.

Soon, we will no longer accept the submission of print versions of articles, only submissions made on-line. To this end, our editorial staff is already participating in a training program at BIREME and, as of the year 2009, the entire submission and peer-review process will be carried out on-line at the SCIELO web site.

Articles may now have up to five authors at most. A greater number of authors may exceptionally be permitted, but only if a justification is presented and deemed acceptable by the Editorial Board.

Lastly, bibliographical references should now be presented according to order of citation in the text, and no longer alphabetically. We would also like to remind authors of the importance of citing articles previously published in the BOR when preparing their manuscripts for submission to our journal.

We trust that these changes, together with the other measures taken to update our editorial policy, will help achieve an even higher level of excellence and will ultimately aid - with the participation of all - in offering the contribution made by the Brazilian Oral Research to the international scientific community. 